\title{
A METHODOLOGY TO INCORPORATE RISK AND UNCERTAINTY IN ELECTRICITY POWER PLANNING ${ }^{1}$
}

\author{
Maria João Santos, ${ }^{1}$ Paula Ferreira ${ }^{1 *}$ and Madalena Araújo ${ }^{1}$ \\ ${ }^{1}$ ALGORITMI Research Centre, School of Engineering, University of Minho, Portugal \\ * Corresponding author: paulaf@dps.uminho.pt, University of Minho, Guimarães, Portugal
}

\begin{abstract}
Deterministic models based on most likely forecasts can bring simplicity to the electricity power planning but do not explicitly consider uncertainties and risks which are always present on the electricity systems. Stochastic models can account for uncertain parameters that are critical to obtain a robust solution, requiring however higher modelling and computational effort. The aim of this work was to propose a methodology to identify major uncertainties presented in the electricity system and demonstrate their impact in the longterm electricity production mix, through scenario analysis. The case of an electricity system with high renewable contribution was used to demonstrate how renewables uncertainty can be included in long term planning, combining Monte Carlo Simulation with a deterministic optimization model. This case showed that the problem of including risk in electricity planning could be explored in short running time even for large real systems. The results indicate that high growth demand rate combined with climate uncertainty represent major sources of risk for the definition of robust optimal technology mixes for the future. This is particularly important for the case of electricity systems with high share of renewables as climate change can have a major role on the expected power output.
\end{abstract}

\section{KEYWORDS}

Uncertainty; Electricity Planning; Optimization Model; Monte Carlo Simulation; Renewable Energy Sources

\section{INTRODUCTION}

Electricity is an indispensable good for society development and growth of a nation, stimulating the economic and technological development of a country [1]. Electricity has special characteristics that make it very different from other commodities traded in competitive markets, namely the need for instant and continuous generation and consumption, non-storability, high variability in demand over a day and season and non-traceability.

Electricity power systems are large-scale, complex engineering systems requiring short- and longterm electricity power planning and management decision making. All these problems have in common the need to reach solutions that minimizes the total system cost while meeting electricity demand at every time in the planning horizon. However, single cost minimization is no longer an acceptable objective and sustainability and resilience concerns are driving electricity systems to adapt and evolve, forcing to consider relations within society and environment, technology development and political goals [2]. These transformations had increased uncertainties in shortand long-term, bringing with it more complexity to the planning process and increasing uncertainty in the decision-making process.

One efficient technique recognized and used worldwide for energy planning is scenario generation [3]. Scenarios help to explore what, how and if future pathways are feasible to achieve predefined goals. Traditionally, a set of future scenarios is built on assumptions and constraints, based on deterministic values to all variables and parameters. Even with a posteriori sensitivity analysis, that allows determining which variable(s) influences most electricity power planning, uncertainties remain unquantified [4]. However, not properly considering uncertainties when

\footnotetext{
${ }^{1}$ Santos, MJ; Ferreira, Paula; Araújo, Madalena (2016) “A methodology to incorporate risk and uncertainty in electricity power planning”, Energy, Vol. 115, 1400-1411.
} 
modelling electricity power systems, and particularly the possible correlations between them [5], can turn seemingly cost-effective results into obsolete and inadequate options [6]. This is precisely the focus of this work, addressing the inclusion of uncertainty on the design of robust electricity scenarios. Although different uncertainties in the energy systems can be recognized including technical and economic ones [7], for the sake of simplicity this work will mainly address uncertainty related to operational parameters, namely demand and generation values in power systems, in particular renewable power output.

The main objective of this work is then to propose a methodology to incorporate risk and uncertainty in electricity power planning, supported on deterministic optimization models combined with Monte Carlo Simulation of uncertain operational parameters. The application of this methodology is deemed to be relevant for the design of generation expansion plans and for the evaluation of its robustness under uncertain operational conditions. The contribution of the paper is then twofold. Firstly, a methodology to deal with uncertainty in operational parameters is presented, particularly well-suited for systems with high renewable share. Secondly, the proposed methodology is demonstrated for an electricity system close to the Portuguese as an example of a system with high renewable integration and aiming to show the contribution of the approach to support robust energy decision making under uncertain future conditions.

The paper is organized as follows. A review on power systems' uncertain parameters and its inclusion in planning models follows this introduction. Then, the methodology used in this study is presented and, subsequently, the results and discussion are detailed. At last, the main conclusions of this work are shown.

\section{RISK AND UNCERTAINTY IN ELECTRICITY SYSTEMS}

The electricity sector is characterized by a high level of uncertainty and risk, resulting not only from its close relationship with an increasingly dynamic policy and regulatory framework but also from its high sensitivity to parameters such as climate conditions, economic environment or social perception. Important uncertainties and risk factors for electricity systems are presented in Table 1 proposing and describing 5 main categories and risk sources respectively.

Economic risk encompasses not only microeconomic aspects of the project, such as the uncertainty related to the fuel prices or business taxes, but also macroeconomic parameters, namely electricity market regulation and national economic growth [7].

Geopolitical risks are particularly relevant in systems depending on the external supply of electricity and/or fossil resources (coal, natural gas and oil). Political instability, between and within countries, may reproduce severe risks to the security of electricity supply, such as prices volatility, disruption of supply chains or degradation of international relationships [8]. Sociocultural risks are also permanently present when defining a plan or strategy for the electricity system, because local communities can create barriers to their construction or, on the other hand, encourage their development, according to their perception about different technologies [9]. The issue of social and cultural acceptance as important risk factors for the design of electricity plans and projects has motivated different works aiming to analyse the perception of population towards different energy options. Some examples include the studies on local communities acceptance of wind onshore power plants for Italy [10] and for China [11] or on the public opinion about the deployment of wind, solar, hydro and biomass technologies in Portugal [12].

Uncertainties in the energy sector driven by climate change and environmental constraints have gained attention in recent years as documented in many works [13]-[16]. A review of the vulnerability of the energy sector to climate change was conducted by Schaeffer et al. [13] comprising the contribution of relevant authors within their strategic studies, research workshops, development forums and international conferences on the climate and energy subject. This review demonstrated overall impacts on each renewable and fossil fuel sources affecting resource endowments, energy supply, transmission, distribution and transfers, energy use, infrastructure siting and finally, cross-sector impacts. Pilli-Sihvola et al.[14] demonstrated a significant and clear relationship between electricity demand and temperature variation. They argue that climate warming will lead eventually to a decrease in future electricity costs for Central and North Europe due to a decrease in heating needs, in opposition to an increase of the electricity costs in Southern Europe in consequence of the increase of cooling needs. In another study, encompassing the 
vulnerability of the Brazilian energy system to climate change, Lucena et al. [16] demonstrated its impacts on the hydropower generation and liquid biofuels production, and later, in the wind power potential [15].

Other studies have emphasised the technical uncertainties related to the large contribution of sources of variable output in the power systems, namely wind and solar power. Ludig et al. [17] analysed low carbon scenarios for the German electricity considering as uncertainties both the long-term electricity demand and the large-scale availability of offshore wind and carbon capture and storage (CCS) units. In the work of Pérez-Arriaga [18], the author examines the large scale penetration of intermittent renewables technologies in the electricity sector and its impacts on the system's operation and reserves requirements, flexibility and stability conditions, system's costs and market prices. The uncertainty related to the technology learning rate and costs estimates was investigated by Levi and Pollitt [19], considering the cases of three important technologies for the UK electricity system - nuclear, wind offshore and coal with carbon capture and storage (CCS).

Table 1. Uncertainties and risk sources in electricity systems.

\begin{tabular}{|l|l|l|}
\hline Categories & Description & Risks and uncertainties \\
\hline Economic & $\begin{array}{l}\text { Risks arising from the financial } \\
\text { aspects of the project, the market } \\
\text { conditions and the economic growth } \\
\text { of a country. }\end{array}$ & $\begin{array}{l}\text { Project capital costs } \\
\text { Commodities prices } \\
\text { Operational costs } \\
\text { Interest rates } \\
\text { External costs }\end{array}$ \\
\hline Geopolitical & $\begin{array}{l}\text { Risks arising from political decisions } \\
\text { of one country's foreign affecting } \\
\text { another country or region. }\end{array}$ & $\begin{array}{l}\text { National policies } \\
\text { International agreements } \\
\text { Environmental regulation }\end{array}$ \\
\hline Sociocultural & $\begin{array}{l}\text { Risks arising from divergences on } \\
\text { social and cultural characteristics of } \\
\text { different communities. }\end{array}$ & $\begin{array}{l}\text { Behavioural change } \\
\text { Future electricity demand } \\
\text { Social acceptance }\end{array}$ \\
\hline Environmental & $\begin{array}{l}\text { Risks related to the influence of the } \\
\text { environmental conditions on the } \\
\text { performance of the electricity system. }\end{array}$ & $\begin{array}{l}\text { Extreme climatic events } \\
\text { Climate change } \\
\text { Natural accidents and catastrophes }\end{array}$ \\
\hline Technical & $\begin{array}{l}\text { Risks related to topological and } \\
\text { operational conditions of the } \\
\text { electricity system. }\end{array}$ & $\begin{array}{l}\text { System's infrastructure } \\
\text { Reliability of resources } \\
\text { Learning rate } \\
\text { Failures and forced outages }\end{array}$ \\
\hline
\end{tabular}

\subsection{UNCERTAINTY INCLUSION IN OPTIMIZATON MODELLING}

Deterministic models are not primarily intended to deal with uncertainty but, this may be achieved by a simple sensitivity analysis or by extensive simulation. This last option frequently requires the use of a technique recognized as Monte Carlo Simulation, widely used for the analysis of problems involving many and potentially correlated uncertainties, allowing the assignment of a probability for respective output [5]. Monte Carlo is actually a stochastic method that allows the representation of uncertain parameters as probability density function (PDF) that may be used as inputs for the deterministic models.

Stochastic models are recognized as the formal approach to deal with uncertainty specifically, which had bridged the gap between deterministic models and uncertainty analysis. In stochastic models, randomness of uncertain parameters is incorporated into problems formulation and retrials calculated in order to better fit the uncertain parameters in space, in the search for the optimal solution. Nevertheless, the mathematical formulation of stochastic models is rather complex, in theory and practice, and thus, specialized knowledge and time efforts are needed to develop a stochastic optimization model for the power system planning [20].

The representation of uncertainty in the planning model can be in the form of interval, fuzzy set, probability distribution or multiple uncertainties [21]. Represented as an interval, possible values for the uncertainty are comprised within minimum and maximum limits, without knowledge of the distribution of the uncertain parameter. Fuzzy sets express the uncertainty also within an interval, but with a complement of a possibilistic distribution, such as the most likely value that 
the uncertain parameter can assume. Probability distribution expresses the uncertainty as a PDF, based on historical data and/or literature review or even experience from the stakeholders or decision makers. Multiple uncertainties allow the uncertainty to be represented as a combination of two or three previous forms (interval, fuzzy set and probability distribution).

Kim et al. [22] focused their work on the uncertainties facing the electricity production costs of conventional and renewable technologies. They applied Monte Carlo simulation to handle uncertainties, such as learning rate of technologies, fuel prices and carbon prices and assuming a normal distribution for all the uncertain parameters. Pye et al. [4] explored the uncertainties affecting policy goals to the transition of the UK energy systems to meet decarbonisation and security goals. The uncertainties tackled were investment costs of power generation technologies, building rates, biomass availability and resources prices (fossil fuel and biomass), for which the PDF were assumed to be triangular distribution, in view of lack of data.

Several studies were carried out in order to compare the pros and cons of both deterministic and stochastic approaches. Fortes et al. [6] analysed the fragilities of the Portuguese power system associated with the development of deterministic long term energy scenarios. A stochastic approach was adopted, using fossil energy prices and energy demand as uncertain parameters, and the main conclusion of the work was that different drivers result in divergent energy scenarios. Loulou et al. [20] analysed alternative climate targets under different cooperation regimes by groups of countries, by both deterministic and stochastic optimization models. The deterministic approach was found not suitable to produce results with mixes of choices, which could only be found by stochastic modelling, although this could be computationally cumbersome. Cedeño \& Arora [23] made a comparison between deterministic and stochastic optimization for the problem of transmission network expansion planning. They emphasized that deterministic models can produce higher cost impact in the plan when the demand deviate from the assumed fixed scenario, notwithstanding the computational complexity of the stochastic approach.

Another technique designed specifically to analyse complex and uncertain systems is the Exploratory Modelling and Analysis (EMA), an iterative and question-driven research methodology that resources to computational experiments [24]. With this technique, many scenarios are designed, allowing the planners to explore the consequences or implications of the uncertain assumptions in the overall system being analysed [25]. The final goal is to define a set of uncertain scenarios and provide to decision-makers insights of each scenario and trade-offs between them.

This work aims to contribute to the theme of uncertainty on power planning, recognizing that a deterministic approach can be too limited specially in systems characterized by high levels of renewable energy sources (RES) and as such strongly dependent on the availability of the underlying renewable resources. The proposed methodology should provide a contribution to tackle these challenges via a simplified stochastic approach able to face major uncertain parameters. To the best of the authors' knowledge, no such simplified approach has been proposed and demonstrated in the literature for a case study based on real operating conditions.

\section{METHODOLOGY}

A set of parameters considered in electricity systems were selected to the study. The selection process was carried out bearing in mind the uncertainties that could affect mostly the long-term electricity power planning for a system with characteristics close to the Portuguese one. For this purpose, a Wilson matrix [26] was used, a simple qualitative matrix that can attribute a relative risk degree to variables, considering the uncertainty level and the impact in the electricity system. For each group of uncertain parameters, both qualitative and quantitative analysis was made. Qualitative analysis relied on literature while quantitative analysis was supported on real data provided from national reports and energy production-related institutions.

The data to perform the analysis of time variability of renewable sources (wind, solar and hydro) were obtained from the electricity production within frames of 15 minutes, since 2007, provided from REN - Redes Energéticas Nacionais. For each RES technology, the capacity factor (CF) was calculated. Capacity factor expresses the ratio between the actual electricity produced by a 
given power plant and the theoretical maximum achieved if the power plant would operate full time. Capacity factor was used due to its dependence on the regime flow [27].

The data to perform the analysis of the demand were collected from the results of the most recent national reports [28]-[30].

Uncertainty analysis was conducted with statistical analysis tools firstly used to adjust the behaviour of each variable studied, in each month, into a PDF that better fits its pattern. Then, correlations between variables were determined, according to the Pearson correlation coefficient, and integrated in the respective PDF of each variable. Thereafter, Monte Carlo Simulation was used to simulate combinations of variables in each month, resulting in a PDF for the capacity factor of each RES technology for each month. Each PDF represents then a wider range of possible combinations of correlated variables and the probability of occurrence of such combinations. According to Amer et al. [31], when more than two uncertain parameters are involved, the standard approach for scenario generation should be no less than three and no more than eight scenarios. Hereupon, five RES scenarios were created selecting five possible combinations obtained from Monte Carlo Simulation and also a reference scenario, this last one based on the average RES power production in the Portuguese electricity system for the 20082014 period.

For scenario modelling, [32] model for generation expansion planning was adapted and expanded. The model solves the generation expansion planning (GEP) problem for a 20 year' time horizon considering the minimization of the system' total costs under a set of constraints including total $\mathrm{CO}_{2}$ emissions released. $\mathrm{CO}_{2}$ emissions allowances are also included in the cost function as a proxy for environmental externalities valuation. Objective function and main assumptions included in the model are presented in Annex I. The main results of the model are total costs and emissions released by the electricity production system for the entire period analysed, as well as a combination of different electricity generation options and their contribution to the electricity production. These power scenarios were then fully characterized and are expected to represent relevant information for supporting future decisions.

The proposed methodology is summarized in Figure 1including the four main steps previously outlined: (1) Selection of risk and uncertain parameters, supported on a qualitative approach; (2) Definition of probability functions and correlation values for the selected parameters, according to historical data series and statistical analysis; (3) Generation of combined RES scenarios through Monte Carlo simulation and (4) Adoption of a deterministic generation expansion planning model for the final outcome of presenting optimal electricity power scenarios.

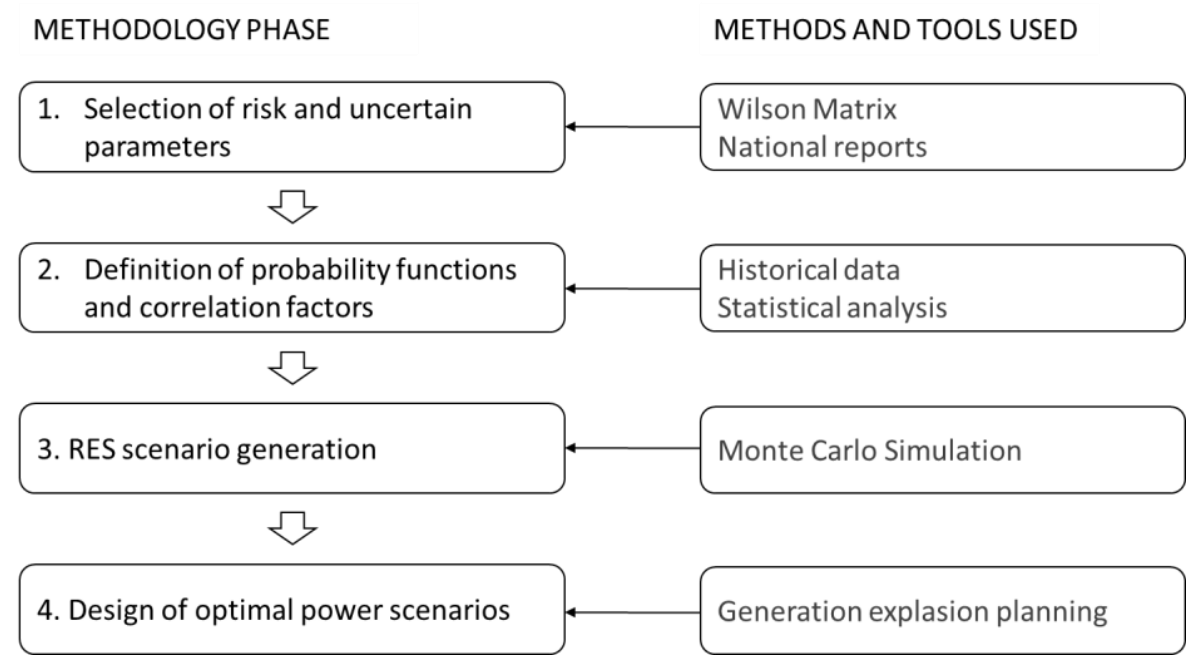

Figure 1 - Methodology applied to the research study. 


\subsection{DESCRIPTION OF THE CASE}

For the simulation, a case close to the Portuguese electricity system was used. The system is characterized by a large contribution of hydro, wind and fossil fuel power technologies (coal and natural gas). Although the Portuguese system is interconnected with Spain, the model assumes here a close (island) system, which can bring advantages to voluntary decision making on import/export decisions as discussed in [33].

In 2014, renewable energy sources (RES) technologies contributed to about $62 \%$ of the total electricity production. The total installed power reached $17841 \mathrm{MW}$, of which 5585 from fossil fuel thermal power plants, $5270 \mathrm{MW}$ from large hydro and run-of-river power plants, $4541 \mathrm{MW}$ from wind power and $2445 \mathrm{MW}$ from other RES power plants [34]. In fact, the integration of RES in the power system is the main driving force for Portugal to achieve global goals in respect to the reduction of GHG emissions. Figure 2 describes the historical evolution of the installed power of non-large hydro RES technologies in Portugal since 2007. Wind onshore is already a well-developed technology and, along with large-hydro (dams and run-of-river), has a major role in the system. One aspect that deserves particular attention is the substantial integration of solar photovoltaic (PV) technology in the electricity matrix since 2007. As for mini-hydro and biomass power plants, the installed power of both technologies remained considerably stable during this period and in particular since 2010.

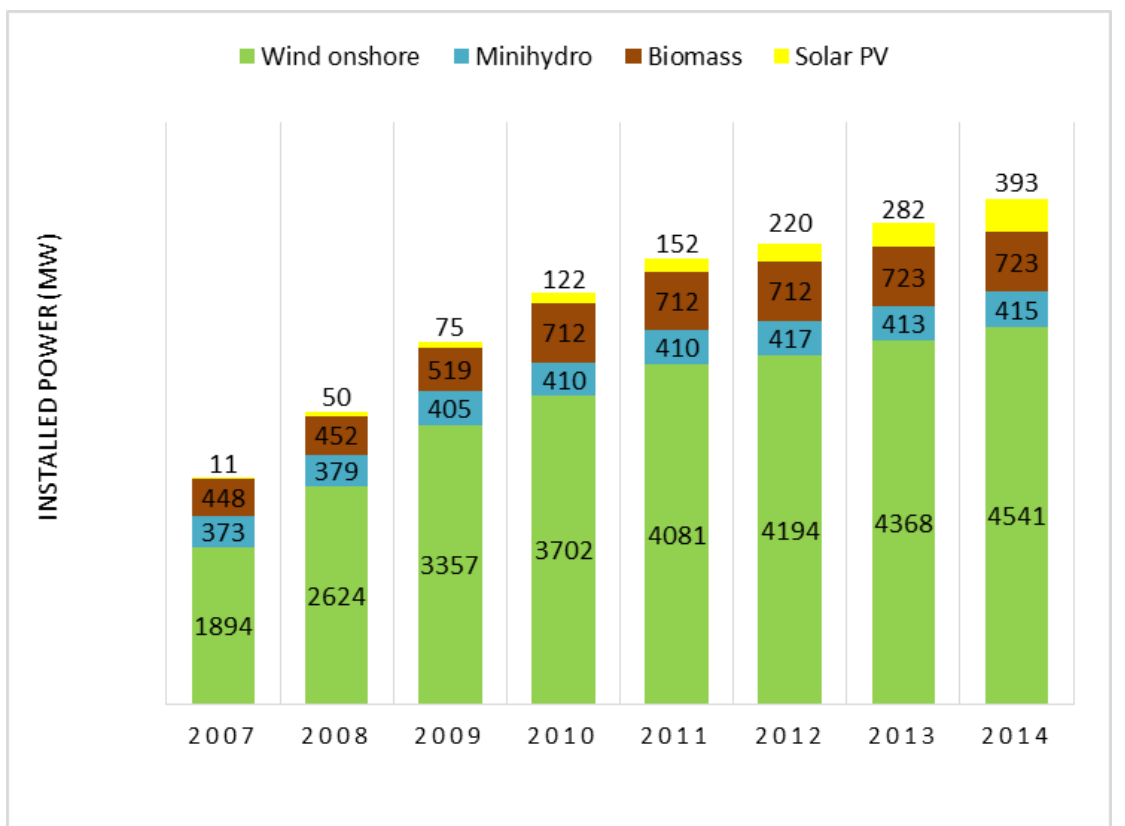

Figure 2 - Installed power for electricity generation from RES technologies in Portugal since 2007 (data obtained from [34]).

According to the recent strategic plan for the Portugal sustainable future, it is expected to achieve $31 \%$ of renewable production in the final energy consumption until 2020 and $40 \%$ until 2030 [35]. Additional targets include 30-40\% reduction in renewable energy prices and $40 \%$ reduction in GHG emissions until 2030.

Despite its advantages to promote the desired sustainable pathway, the integration of RES in the electricity system is perhaps one of the main challenges for long-term electricity power planning. The challenge is allied to the high level of uncertainty brought by intermittent sources. Intermittency comprises two different aspects: limited-controllable variability and partial unpredictability [18]. Controllable variability refers to the possibility of adjusting and directing the flows, and thus technologies that can store energy are highly controllable, such as large hydro with reservoirs. The unpredictability refers to the knowledge of the likelihood (or not) of an event to occur, such as a dry or rainy day, for instance. Another risk factor that can increase RES relateduncertainty is climate change. Global warming will increase evaporation and/or reduce 
precipitation [13], putting at risk the water reserves and decreasing PV cells efficiency, for instance.

Future demand is one major uncertainty facing electricity power planning, since it is naturally driven by population growth, gross domestic product and employment, among others, and eventually the correlations between them [27]. As for Portugal, the electricity consumption has grown considerably since 2000 , at a rate of about $2.5 \%$ per year until 2010 . Afterwards, the electricity consumption has seen a decrease until near $1.6 \%$ a year, as illustrated is Figure 3.

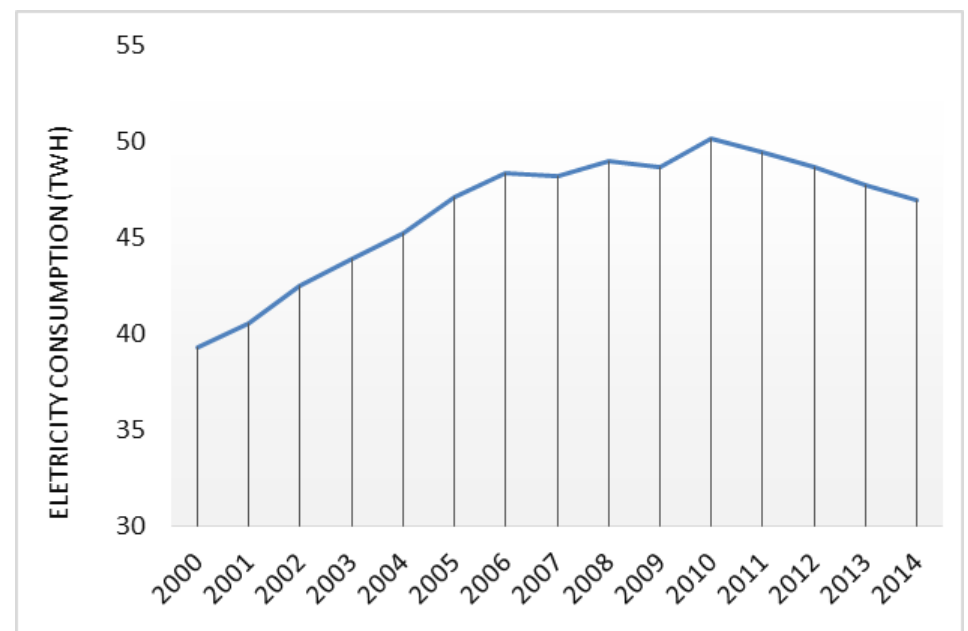

Figure 3 - Evolution of the electricity consumption in Portugal, in TWh for the last 15 years (data collected from [28] and [34]).

There is a serious need of supporting long-term electricity planning on the possible outcomes of electricity consumption evolution. The described case clearly demonstrates that tendencies of the past on electricity consumption hardly can be assumed as representative of the future. Demand projection is then an important uncertainty factor to be considered.

\section{RESULTS AND DISCUSSION}

4.1. QUALITATIVE ANALYSIS

The classification of each variable analysed in the Wilson Matrix is presented in Figure 4. Wind availability was classified as a "critical scenario driver" in time and space. Also wind power is a significant player in the proposed electricity system, with growing perspectives at a global scale. Solar availability is also unpredictable in the long term but today, solar power contributes with a low percentage to the national electricity production system, and as such it is assumed that it does not impact the system as much as wind availability. Solar availability was thus classified as an "important scenario driver". 


\section{DEGREE OF UNCERTAINTY}

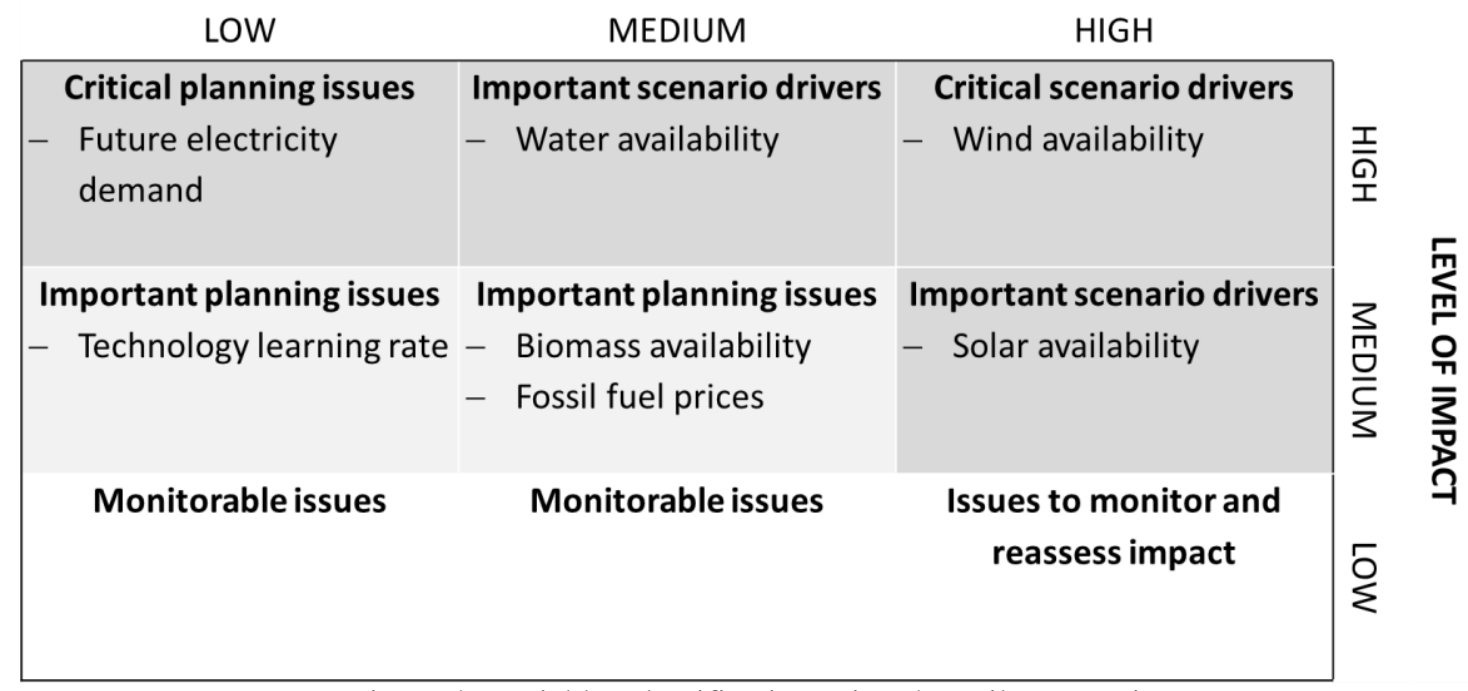

Figure 4 -Variables classification using the Wilson Matrix.

Water availability was also classified as "important scenario driver". Water availability has huge impact on the proposed electricity power system and contributes to a large extent to the backup system and security of supply. Nevertheless, its degree of uncertainty is lesser than for wind or solar availability, because although being highly affected by climate conditions, large hydropower technologies have reservoirs that can store energy providing some controllability and flexibility to the system management.

Electricity demand was classified as a "critical planning issue" since it plays an obvious role in the electricity system, driving the electricity power production and the backup activation. However, and even being the historical data not representative of the evolution of the electricity demand in the last years, there are several methods and tools designed to provide reliable demand projections as reviewed in [37] or recently illustrated in a case study for Spain [38].

At last, technology learning rate, biomass availability and fossil fuel prices were assigned in "important planning issues". Technology learning rate has a lower uncertainty degree compared with biomass availability, because it is a process with an evolution pattern and relevant only for long term power planning. But they both have a medium impact on the electricity power planning: biomass availability has a relatively significant role in the electricity production and technology learning rate directly affects the investment and fixed costs of the electricity generation options. Fossil fuel (coal and natural gas) prices largely depend on the economic and geopolitical conditions of the external supplier, as Portugal totally relies of fossil fuels imports. Although fossil thermal power plants have still an important role on electricity production, both the diversification and RES increase strategies contribute to reduce risk related to the external supply of fuels.

According to Maack et al. [39], the key elements for a good scenario plot are the variables positioned in the categories "critical planning issues" and "critical scenario drivers". Nevertheless, the variables positioned in the category "important scenario drivers" are also deemed to be important for demonstration of the methodology using the proposed case. Therefore, the uncertain parameters selected for this study were renewable sources availability (wind, solar and water) and future electricity demand.

\subsection{QUANTITATIVE ANALYSIS}

Data collected for the period 2007-2014 (quarter of an hour data) for each of the considered RES technologies at each month, were adjusted to the PDF that better fits each time series. After the adjustment, a Monte Carlo simulation was run. As an example, the results for January for wind (green line), solar (yellow line), minihydro (light blue line) and run-of-river (dark blue line) are presented overlaid in Figure 5. 


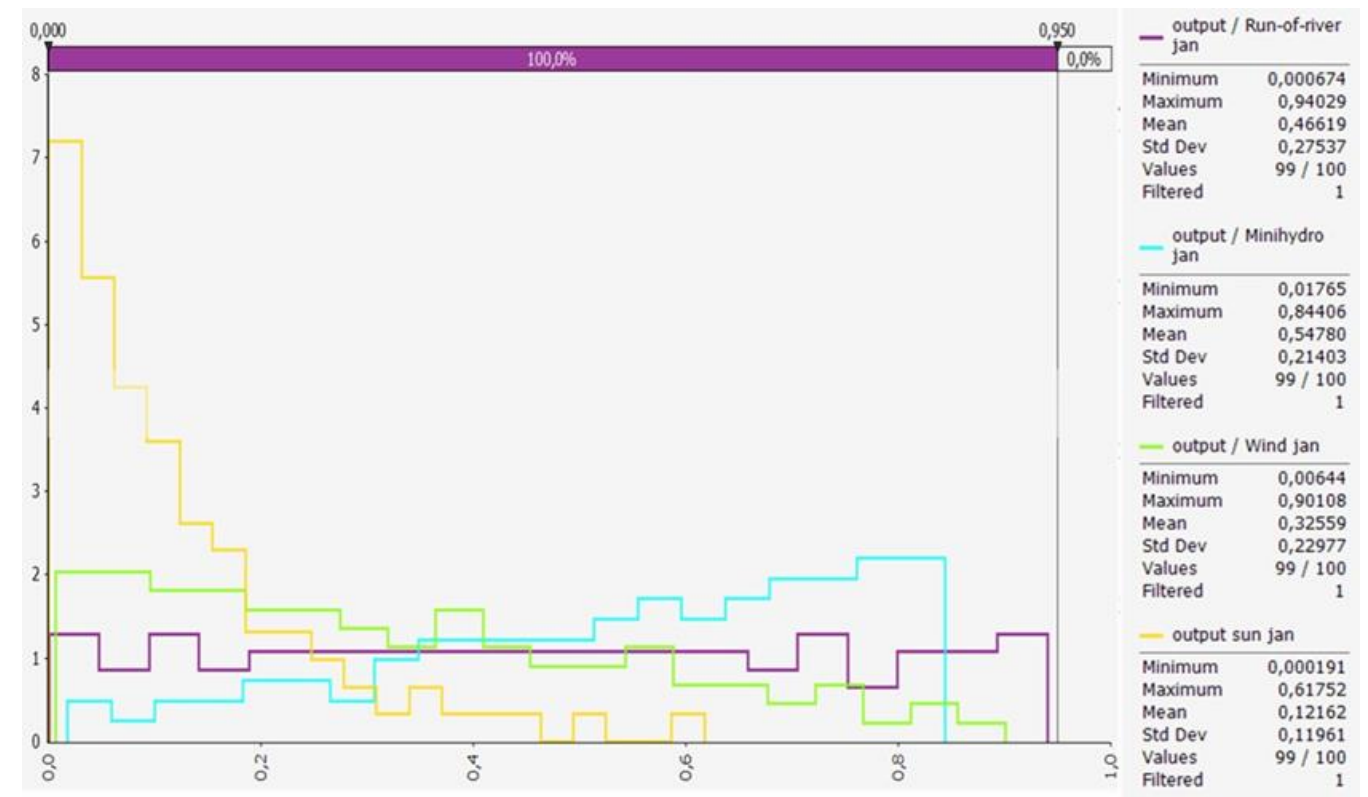

Figure 5 - Probability density distribution of the CF of each technology, in January.

Each RES displays a particular behaviour that is different between them and different at each month. This behaviour, related to the capacity factor of the respective electricity generation technology, could be translated into a PDF. Each PDF has its own statistical parameters characterizing the distribution as detailed in Annex II. For example, following Figure 5 an adjustment for different PDFs for each technology was tested, concluding that, in January, triangular distribution best fits both wind onshore and minihydro technologies, while solar PV technology is closer to an exponential distribution and run-of-river technology to an uniform distribution.

Table 2 shows the statistical parameters for each PDF better fitting each technology at each month. Wind onshore technology reveals a behaviour along the year that can be expressed as a triangular distribution from January to April and a beta distribution the rest of the year, except during the months September and October for which a gamma distribution is the best fit. As for solar technology, its capacity factor exhibits an exponential distribution during the entire year, except in August where the best fitting function is a gamma distribution. Water-based technologies, namely minihydro and run-of-river, present miscellaneous distributions, varying from triangular, exponential, uniform, beta, gamma, Weibull and Pearson.

After the adjustment of the CFs of each RES technology to a PDF, correlations factors between different RES technologies were calculated. Based on all this information, Monte Carlo simulations were conducted to obtain combined monthly RES scenarios and probability of occurrence. From this, five possible combinations of renewables sources, in each month, were used to construct scenarios and compare them with a reference scenario. These scenarios were designated as follows:

- Business-as-usual scenario (BUS), reference scenario considering the average capacity factor of each power generator from 2008-2014;

- Lower central (LC), Central (C) and Upper central (UC), intermediate scenarios presenting combinations of CF for RES technologies with moderate resource availability;

- Pessimist (Pess) and Optimist (Opt), extreme scenarios presenting respectively, very low and very high availability of all RES resources.

The capacity factor range of each technology characterizing each scenario, along a year, is illustrated in Figure 6. 
Table 2 - Probability distribution for each technology, at each month.

\begin{tabular}{|c|c|c|c|c|}
\hline Month & Run-of-river & Minihydro & Wind onshore & Solar PV \\
\hline Jan & $\begin{array}{l}\text { Min: } 0 \text { a) } \\
\text { Max: } 0,94151\end{array}$ & $\begin{array}{l}\text { Min: } 0^{c)} \\
\text { M. likely: } 0,83312 \\
\text { Max: } 0,85915\end{array}$ & $\begin{array}{l}\text { Min: } 0,0017^{c)} \\
\text { M. likely: } 0,0017 \\
\text { Max: } 0,95567\end{array}$ & $\beta: 0,12569^{\mathrm{e})}$ \\
\hline $\mathrm{Feb}$ & $\begin{array}{l}\text { Min: } 0 \text { a) } \\
\text { Max: } 0,9516\end{array}$ & $\begin{array}{l}\text { Min: } 0^{\mathrm{c}} \\
\text { M. likely: } 0,83471 \\
\text { Max: } 0,8706 \\
\end{array}$ & $\begin{array}{l}\text { Min: } 0,00049^{\mathrm{c})} \\
\text { M. likely: } 0,00049 \\
\text { Max: 0,9711 }\end{array}$ & $\beta: 0,1811^{\mathrm{e})}$ \\
\hline Mar & $\begin{array}{l}\text { Min: } 0 \text { a) } \\
\text { Max: } 0,92255\end{array}$ & $\begin{array}{l}\text { Min: } 0,01053^{\text {a) }} \\
\text { Max: } 0,87367\end{array}$ & $\begin{array}{l}\text { Min: } 0,00324^{c)} \\
\text { M. likely: } 0,00708 \\
\text { Max: } 0,97915\end{array}$ & $\beta: 0,22597^{\mathrm{e})}$ \\
\hline Apr & $\begin{array}{l}\text { Min: } 0^{\text {a) }} \\
\text { Max: 0,94174 }\end{array}$ & $\begin{array}{l}\alpha_{1}: 1,1079 \text { b) } \\
\alpha_{2}: 1,1394 \\
\text { Min: } 0,0079746 \\
\text { Max: } 0,8745\end{array}$ & $\begin{array}{l}\text { Min: } 0^{\text {c) }} \\
\text { M. likely: } 0,01753 \\
\text { Max: } 0,8972\end{array}$ & $\beta: 0,2579^{\mathrm{e})}$ \\
\hline May & $\begin{array}{l}\alpha_{1}: 1,2247^{b)} \\
\alpha_{2}: 1,7381 \\
\text { Min: } 0 \\
\text { Max: } 0,78098 \\
\end{array}$ & $\begin{array}{l}\alpha_{1}: 1,8939^{b)} \\
\alpha_{2}: 4,1314 \\
\text { Min: } 0,019238 \\
\text { Max: } 0,89499 \\
\end{array}$ & $\begin{array}{l}\alpha_{1}: 1,2763^{b)} \\
\alpha_{2}: 4,3072 \\
\text { Min: } 0,00488 \\
\text { Max: } 1\end{array}$ & $\beta: 0,29911^{\mathrm{e})}$ \\
\hline Jun & $\begin{array}{l}\text { Min: } 0^{\text {c) }} \\
\text { M. likely: } 0,00006 \\
\text { Max: 0,80895 }\end{array}$ & $\begin{array}{l}\alpha: 2,3397^{\mathrm{f}} \\
\beta: 0,06408\end{array}$ & $\begin{array}{l}\alpha_{1}: 1,6229^{b)} \\
\alpha_{2}: 6,4285 \\
\text { Min: } 0,00208 \\
\text { Max: } 1\end{array}$ & $\beta: 0,32034^{\mathrm{e})}$ \\
\hline Jul & $\begin{array}{l}\alpha: 1,4138^{\mathrm{d})} \\
\beta: 0,18339\end{array}$ & $\begin{array}{l}\alpha: 1,6548^{\mathrm{d})} \\
\beta: 0,072582\end{array}$ & $\begin{array}{l}\alpha_{1}: 1,6129^{b)} \\
\alpha_{2}: 4,1045 \\
\text { Min: } 0,00308 \\
\text { Max: } 0,81921\end{array}$ & $\beta: 0,35114^{\mathrm{e})}$ \\
\hline Aug & $\beta: 0,12947^{\mathrm{e})}$ & $\begin{array}{l}\alpha: 2,0859^{\mathrm{d})} \\
\beta: 0,050832\end{array}$ & $\begin{array}{l}\alpha_{1}: 1,6455^{b)} \\
\alpha_{2}: 4,6423 \\
\text { Min: } 0,00319 \\
\text { Max: } 0,85888\end{array}$ & $\begin{array}{l}\alpha: 1,0783^{\mathrm{f})} \\
\beta: 0,25533\end{array}$ \\
\hline Sep & $\begin{array}{l}\text { Min: } 0^{\mathrm{c})} \\
\text { M. likely: } 0,00006 \\
\text { Max: 0,51603 }\end{array}$ & $\begin{array}{l}\alpha: 0,14375^{\mathrm{g})} \\
\beta: 0,11081\end{array}$ & $\begin{array}{l}\alpha: 1,3673^{f)} \\
\beta: 0,1375\end{array}$ & $\beta: 0,25303^{\mathrm{e})}$ \\
\hline Oct & $\begin{array}{l}\text { Min: } 0^{c)} \\
\text { M. likely: } 0,00007 \\
\text { Max: 0,65713 }\end{array}$ & $\begin{array}{l}\mu: 0,14375^{\text {h) }} \\
\lambda: 0,11081\end{array}$ & $\begin{array}{l}\alpha: 1,1331^{\mathrm{f})} \\
\beta: 0,22342\end{array}$ & $\beta: 0,21174^{\mathrm{e})}$ \\
\hline Nov & $\begin{array}{l}\left.\text { Min: } 0,00001^{\mathrm{c}}\right) \\
\text { M. likely: } 0,00003 \\
\text { Max: } 0,71142\end{array}$ & $\begin{array}{l}\text { Min: } 0,00594^{c)} \\
\text { M. likely: } 0,00796 \\
\text { Max: } 0,8795\end{array}$ & $\begin{array}{l}\alpha_{1}: 1,1956^{\mathrm{b})} \\
\alpha_{2}: 1,8293 \\
\text { Min: } 0,00054 \\
\text { Max: } 0,90866\end{array}$ & $\beta: 0,14938^{\mathrm{e})}$ \\
\hline Dec & $\begin{array}{l}\text { Min: } 0,00003^{c)} \\
\text { M. likely: } 0,00003 \\
\text { Max: } 0,9013\end{array}$ & $\begin{array}{l}\text { Min: } 0,00852^{a)} \\
\text { Max: } 0,81908\end{array}$ & $\begin{array}{l}\alpha_{1}: 1,0655^{b)} \\
\alpha_{2}: 1,5667 \\
\text { Min: } 0,00037 \\
\text { Max: } 0,89083\end{array}$ & $\beta: 0,11364^{\mathrm{e})}$ \\
\hline
\end{tabular}

a) uniform distribution, b) beta distribution, c) triangular distribution, d) Weibull distribution, e) exponential distribution, f) gamma distribution, g) Pearson distribution, h) inverse Gaussian distribution 


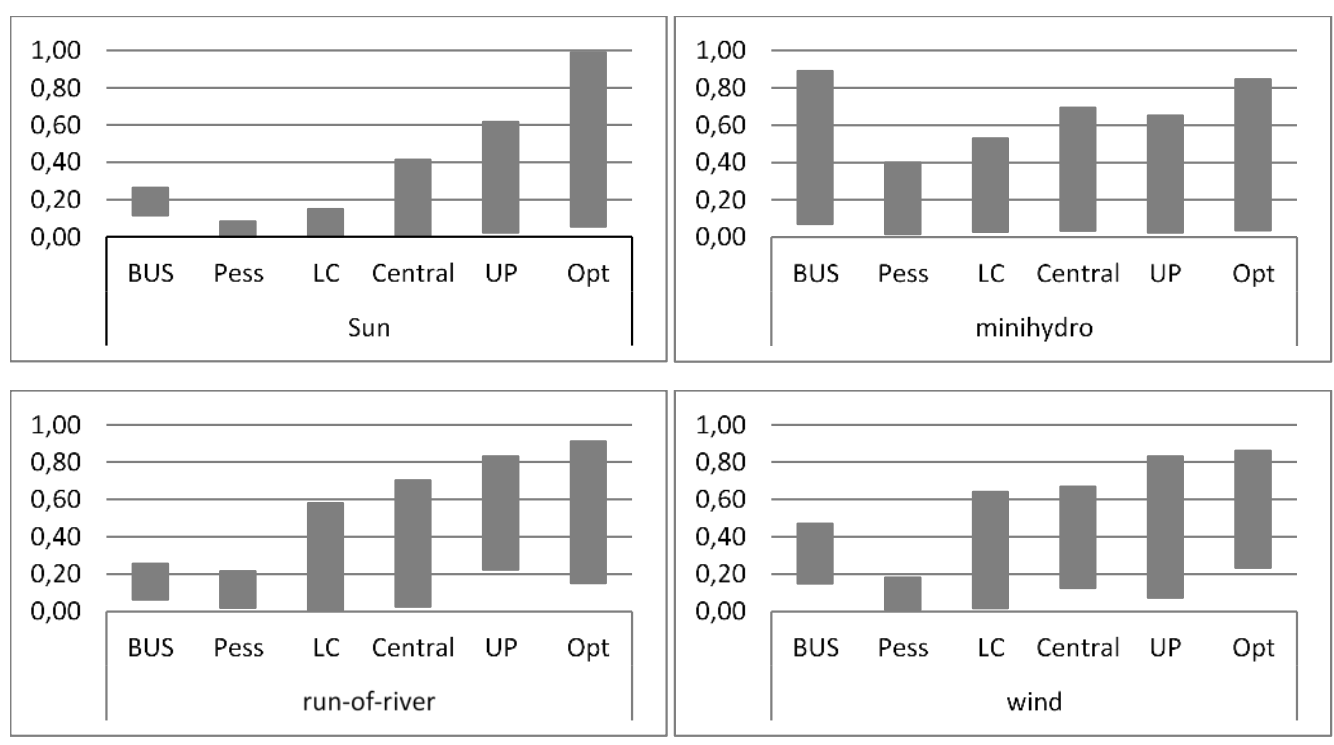

Figure 6 - Capacity factors range of each RES technology, in each scenario.

The data to perform the analysis of the future electricity demand were collected from the results of recent national reports. In the Monitoring Report of the Security of Supply of the National Electricity System for the period 2013-2030 [29], the electricity demand evolution was considered to grow within an interval of $0.8 \%-1.4 \%$, per year. The Development and Investment Plan of the Electricity Transmission Grid 2014-2023 [28] introduces some changes to the previous report, namely the forecasted evolution of future electricity demand was lowered to an interval of $0.8 \%$ to $1.1 \%$ annually growth rate. On the other hand, the Development and Investment Plan of the Electricity Distribution Grid 2015-2019 [30] assumes a bolder prediction of 1.6\% annually demand growth until 2019.

The analysis of the uncertainty of future electricity demand was not performed by Monte Carlo Simulation, due to the lack of extensive data demand projections. Instead, two growth rates were analysed: i) $0.95 \%$, the report's medium value obtained with the most recent data and ii) $2 \%$, a value near the electricity demand growth before 2011 . Using these two different growth rates in scenario generation it is expected to have a wider view of possible outcomes in different electricity systems with high RES share, as illustrated in Figure 7.

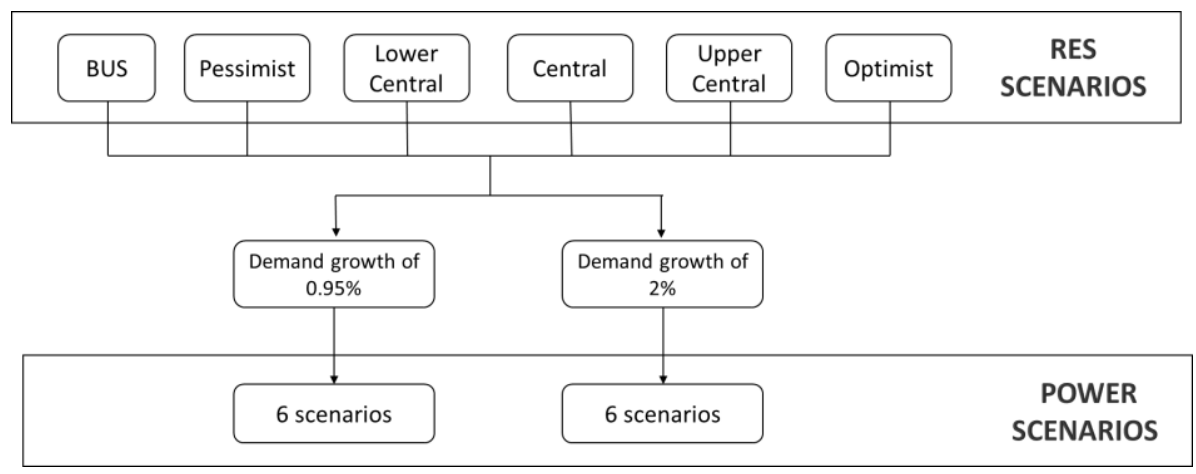

Figure 7 - Scenario construction for the electricity power system.

\subsection{GENERATION EXPANSION PLANNING}

The main indicators for each scenario in 2035 are presented in

Table 3, including the average cost of electricity production, the average $\mathrm{CO}_{2}$ emissions, the total RES share to the electricity system and the overproduction level (excess production). The values for cost and $\mathrm{CO}_{2}$ emissions were obtained directly from the planning model described in Annex 
I, representing the average cost and average $\mathrm{CO}_{2}$ emissions for the entire planning period. RES share was computed as the ratio between total RES power output and total demand in the last year of the planning period. Excess production was computed as the difference between total electricity production and total demand also in the last year of the planning period.

Through a first analysis to results, one remark generalized in all indicators is that the BUS scenario can be positioned between Pessimist and Lower central scenarios. For example, the cost of electricity for BUS scenario is close to the equivalent in the Lower central scenario, while the value of $\mathrm{CO}_{2}$ emissions is between Pessimist and Lower central scenarios.

Following the scenario order from Pessimist to Optimist a consistent decrease in the cost of electricity production as well as in $\mathrm{CO}_{2}$ emissions can be seen. Total RES contribution to the electricity system in 2035 , as well as the excess production, have not such an evident relation between scenarios. In fact, a higher RES share does not mean more productivity, if there is overproduction.

Table 3 shows that an increase in electricity demand can lead to an increase in RES share but can also result on higher excess production for the system. Overproduction comes mainly from wind, solar PV and run-of-river power output as storage other than pumping hydro was not considered in the model. This excess production, is particularly evident in pessimistic scenarios due to the required higher installed power. Costs decreasing for more optimistic scenarios is due to higher values in the capacity factors of RES, resulting in higher RES power output and consequently in significant fuel savings. The same goes for $\mathrm{CO}_{2}$ emissions decreasing, as electricity production by fossil fuels is gradually substituted by RES, significant savings in $\mathrm{CO}_{2}$ emissions could be achieved.

Table 3 - Main indicators for scenario comparison.

\begin{tabular}{|c|c|c|c|c|c|c|c|c|c|}
\hline \multirow{2}{*}{\multicolumn{2}{|c|}{$\begin{array}{c}\text { INDICATORS } \\
\text { Demand growth }\end{array}$}} & \multicolumn{2}{|c|}{$\begin{array}{c}\text { Cost of electricity } \\
\text { production }(€ / M W h)^{1}\end{array}$} & \multicolumn{2}{|c|}{$\begin{array}{c}\mathrm{CO}_{2} \text { emissions } \\
\text { (ton/MWh })^{1}\end{array}$} & \multicolumn{2}{|c|}{$\begin{array}{c}\text { RES share in total } \\
\text { demand }(\%)^{2}\end{array}$} & \multicolumn{2}{|c|}{$\begin{array}{c}\text { Excess } \\
\text { Production }(\%)^{2}\end{array}$} \\
\hline & & $0,95 \%$ & $2 \%$ & $0,95 \%$ & $2 \%$ & $0,95 \%$ & $2 \%$ & $0,95 \%$ & $2 \%$ \\
\hline \multirow{6}{*}{ 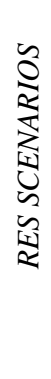 } & BUS & 7,1 & 7,6 & 0,126 & 0,144 & 64,0 & 73,2 & 2 & 11 \\
\hline & Pessimist & 10,8 & 12,7 & 0,153 & 0,149 & 75,4 & 72,8 & 13 & 11 \\
\hline & Lower central & 6,5 & 7,0 & 0,110 & 0,140 & 64,4 & 68,7 & 0 & 7 \\
\hline & Central & 5,5 & 6,3 & 0,090 & 0,127 & 66,0 & 69,9 & 0 & 9 \\
\hline & Upper central & 4,0 & 5,1 & 0,057 & 0,097 & 76,7 & 62,0 & 0 & 0 \\
\hline & Optimistic & 2,4 & 3,1 & 0,023 & 0,045 & 88,8 & 83,5 & 4 & 0 \\
\hline
\end{tabular}

${ }^{1}$ Average value for the planning period; ${ }^{2}$ Last year of the planning period.

Considering now the increase in the electricity demand from $0.95 \%$ to $2 \%$ annual growth, a natural increase in the electricity costs can be observed, resulting from the need of installing additional power plants to match the higher demand, as illustrated in Figures Figure 8 and 9. Taking BUS as an example, with a most likely growth demand of $0.95 \%$ the additional installed power until the last year would be near $1750 \mathrm{MW}$ but with a growth demand of $2 \%$ the required additional power would be about $3700 \mathrm{MW}$.

FiguresFigure 8 and 9 present the proposed new installed capacity for each technology in the system in the last year of the planning period, aiming to analyse the robustness of the BUS scenarios traditionally used on the optimization approach.

In Figure 8, it is shown that total new installed power in BUS, apart from the Pessimist scenario, is very similar to all the others. This may indicate that, with a moderate electricity demand growth of $0.95 \%$ in the next 20 years, this electricity system could be prepared to meet the demand at all time, but with a slight excess production in most extreme scenarios. For most scenarios, favourable conditions of wind, sun and/or hydro would lead to a more efficient electricity system, 
with lower production costs and no excess production. All scenarios present investments on combined cycle gas turbine (CCGT) and hydro power plants, demonstrating the importance of these technologies for a robust system. As for biomass, it tends to have an important role for less optimistic scenarios, which can be attributed to the higher predictability and storage capacity of this resource when compared to other renewables. Further tests on the model assumptions (e.g. for higher RES share) show a similar trend, still demonstrating the importance of these technologies across scenarios. For BUS and Pessimist to Central scenarios, investments on biomass power plants are also required, while for Optimist scenario, a small contribution of solar power units can also be suitable.

Comparing Figure 8 and 9, it is demonstrated that an increase from $0.95 \%$ to $2 \%$ in the electricity demand would lead to additional investments but mostly on the same technological options, with the exception of new investments on wind onshore power plants for BUS scenario. Under the $2 \%$ demand growth rate, the total new installed power in BUS is considerably higher than for the other scenarios, with the exception of the Pessimistic one. All scenarios exhibit new installed power on CCGT power units along with additional hydro power units. New biomass is present in all scenarios with the exception of the Optimistic one. This last one, shows evidence of a large contribution of solar PV for the total new installed capacity taking advantage of the assumed high CF values for this technology.

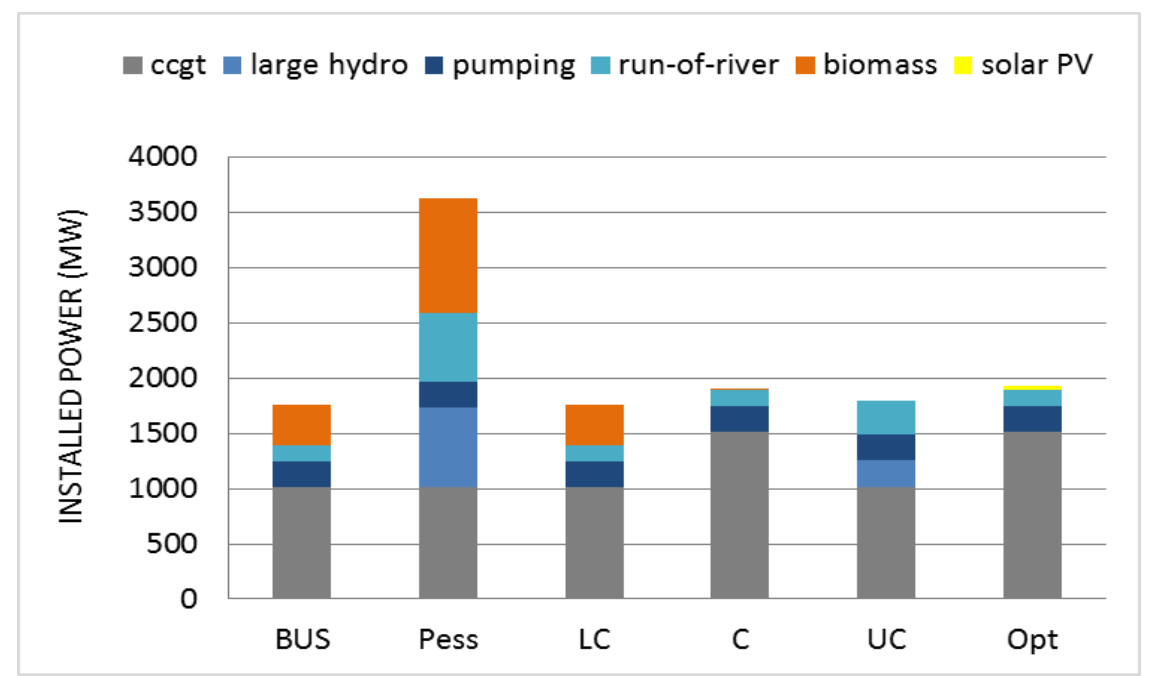

Figure 8 - New installed power from each technology until 2035 , for $0.95 \%$ annual demand growth.

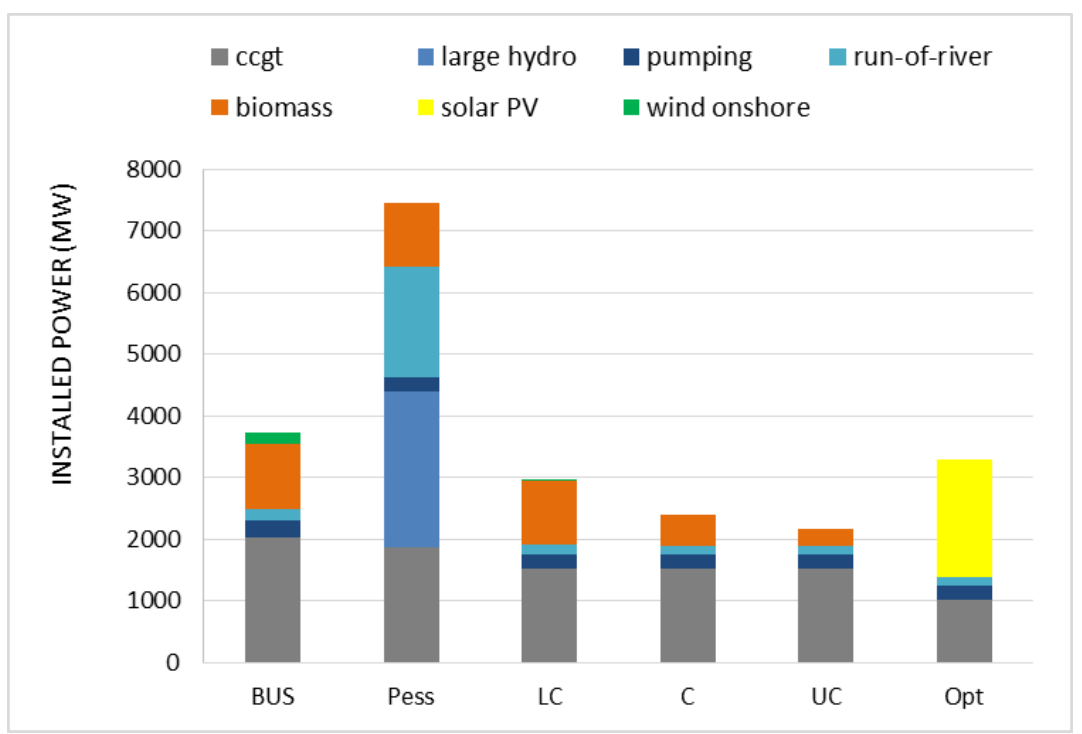

Figure 9 - New installed power from each technology until 2035, for $2 \%$ annual demand growth. 
According to the results, the BUS scenario seems to be less robust for high demand growth perspectives, meaning that the optimal mix of new technologies to add to the system would strongly depends on the RES availability assumptions which in turn are largely affected by the climate conditions. For most of the considered RES scenarios a higher demand growth rate would be compensated not only by new RES power plants but also by new CCGT. This means that high demand growth rate will tend to result in higher costs and higher $\mathrm{CO}_{2}$ emissions. Also, a high demand growth rate does not necessarily lead to a reduction of excess electricity production but in some cases can even increase it.

For low demand growth perspectives, the BUS scenario is close to most of the other scenarios in what concerns the new installed power mix, apart from the pessimistic scenario. This can be explained by the low needs for new installed power, as the already existing power plants would be able to cover most of the demand requirements. This would mean that under the perspective of low demand growth rate, the cost and $\mathrm{CO}_{2}$ emissions would still be largely influenced by climate conditions but the optimal technology mix is less sensitive to these assumptions.

It is also interesting to notice that scenarios with high RES share are frequently associated to excess electricity production, demonstrating that the efficient management of RES in the electricity system requires the inclusion of other options incorporating for example electricity storage or interconnection capacity. Although Portugal is already interconnected with Spain in the Iberian electricity market, for the sake of simplicity, the possibility of market trading was not considered in these simulations. The possibility of the expansion of the test problem to include other technologies, distributed storage and interconnection market strategies can provide further insights to generation expansion planning minimizing the impact of uncertainty on the design of future power plans.

Under deterministic conditions the generation expansion planning problem relies on average historical conditions in order to find an expansion plan that minimizes the generation cost for fixed expected demand. However, the results demonstrate that this BAU scenario may not be optimal under different operating conditions and formulating this problem relying on a probabilistic interpretation of RES parameters can bring additional confidence to decision making. The objective of the presentation was not to be exhaustive on the description of the scenarios, but rather to show a strategy to design possible scenarios based on the statistical characteristics of relevant parameters in a way to improve the performance of decision makers. In fact, when working with generation expansion planning a "deep uncertainty" problem arises, as defined by [40] giving rise to a multiplicity of probabilistic well suited scenarios. Developing robust methods are then required to identify and investigate potential strategies and plans for future scenarios with "deep uncertainty" [41], and also to identify the vulnerabilities of those strategies and the tradeoffs between them. These scenarios can then be considered for the design of adaptive policies as described for example in Hamarat et al. [42], exploring what policies can hold across different uncertainties [25] and turning decisions more robust and creating the basis for resilient energy systems.

In what concerns specifically to the proposed methodology for electricity power planning, it was shown that it can provide a low-time consuming, relatively simple and multi-method methodology to cope with the complexity of incorporating uncertainty and risk analysis in power planning and decision making processes. This methodology exhibits flexibility to be adapted to the analysis of diverse uncertain parameters and risk sources, guided by other objectives than the ones studied in this research. It is also worth mentioning that the proposed methodology enables the planner or decision maker to explore and assign probability distributions for future scenarios, as well as to determine the possible range of the inputs or outputs of the problem to be analysed.

\section{CONCLUSIONS AND FURTHER RESEARCH}

Deterministic models are well-recognized in the electricity power planning field and are presented as a good strategy to develop long-term scenarios. However, these models frequently rely on assumptions of the future behaviour based on fixed parameters and historical data, as if the future is well known in advance. To deal with uncertain parameters, deterministic models can use sensitivity analysis, and so, they are viewed as a useful simple approximation of reality, that is easier to build and interpret than stochastic models. On the other hand, stochastic models, instead 
of using deterministic values, identify uncertain parameters and assign to them probability distributions mapping their possible occurrences, turning into more reliable scenarios but requiring additional resources and higher computational efforts.

This work intended to analyse several uncertain parameters that could affect electricity systems and that should be included in electricity power planning. For this, a methodology combining risk evaluation of the model parameters, Monte Carlo simulation and generation expansion planning with a cost optimization model was proposed and demonstrated for a system close to the Portuguese one. The parameters i) availability of renewable energy sources and ii) future electricity demand were selected as critical uncertain factors, using a Wilson matrix, and then, a qualitative and quantitative analysis of these parameters was made. For the qualitative analysis, several national reports and literature was used, while quantitative analysis was carried with state of the art software for selecting best fit PDF functions for each parameters, perform correlation analysis and generate scenarios. Quantitative analysis had enabled the creation of several possible combinations of uncertain parameters that were used to differentiate scenarios. Six RES scenarios were analysed: a business-as-usual scenario (BUS), two extreme scenarios and three intermediate scenarios. These were then modelled in a GEP cost optimization model and resulted in optimal power scenarios for a 20 years planning period.

The results of this work indicate that the considered case is largely influenced by RES availability assumptions, in particular under high growth electricity demand hypothesis. Ensuring a low growth of electricity demand seems to be not only an important strategy to reach economic and environmental objectives but also to mitigate risk associated with the variability of RES resources. The results also demonstrate that costs, $\mathrm{CO}_{2}$ emissions and fossil fuel importations ratios are clearly related to the assumed capacity factor of RES technologies, specially wind and solarbased. This is particularly important for the case of the electricity systems with high share of RES as climate change can have a major role on the expected RES power output. Capacity factors of these technologies are highly correlated to the regime flows of wind and sun and the choice of the location to implant the power unit is then crucial for the electricity system economics. Also, energy policies promoting technological development and targeting higher efficiency of RES power units can be well suited to tackle climate change impacts increasing the resilience of power systems.

The methodology proposed was presented and tested in order to provide an alternative to the high complex and time consuming stochastic optimization modelling and operation. The analysis of the proposed electricity system showed that a set of power scenarios can be obtained in short running times (just over 2 minutes), supported on previous Monte Carlo simulation of the relevant parameters of the model. The [43] model was demonstrated to be strategic useful for scenario design, combined with uncertainty analysis, but put in evidence also the importance of the assumed data for the design of a robust plan for the future.

Future work should include the validation of the proposed methodology, comparing the results with those obtained with stochastic optimization models. Also, other uncertainties and scenarios should be investigated in order to increase knowledge of overall risks presented in the electricity system and study possible measures to manage them. In particular, climate change projections and their impact on the operating performance of RES technologies are important aspects to be taken into account in future planning models. Finally, the model can be expanded to include not only other technologies for electricity generation but also distributed storage options or/and interconnection capacity that can have a critical role on the management of high RES systems.

\section{ACKNOWLEDGMENT}

This research was supported by a Marie Curie International Research Staff Exchange Scheme Fellowship within the 7th European Union Framework Programme, under project NETEPEuropean Brazilian Network on Energy Planning (PIRSES-GA-2013-612263. The authors wish to acknowledge also the support of ALGORITMI research Centre at University of Minho. This work has been supported by COMPETE: POCI-01-0145-FEDER-007043 and FCT - Fundação para a Ciência e Tecnologia within the Project Scope: UID/CEC/00319/2013. 


\section{REFERENCES}

[1] R. D. Prasad, R. C. Bansal, and A. Raturi, "Multi-faceted energy planning: A review," Renew. Sustain. Energy Rev., vol. 38, pp. 686-699, Oct. 2014.

[2] D. Möst and D. Keles, "A survey of stochastic modelling approaches for liberalised electricity markets," Eur. J. Oper. Res., vol. 207, no. 2, pp. 543-556, Dec. 2010.

[3] P. Fortes, A. Alvarenga, J. Seixas and S. Rodrigues, "Long-term energy scenarios: Bridging the gap between socio-economic storylines and energy modeling" Technol Forecast Soc, vol. 91, pp. 161-178, 2015.

[4] S. Pye, N. Sabio, and N. Strachan, "An integrated systematic analysis of uncertainties in UK energy transition pathways," Energy Policy, pp. 1-12, 2015.

[5] P. Vithayasrichareon and I. F. MacGill, "A Monte Carlo based decision-support tool for assessing generation portfolios in future carbon constrained electricity industries," Energy Policy, vol. 41, pp. 374-392, Feb. 2012.

[6] P. Fortes, J. Seixas, S. Simões, and J. Cleto, "Long Term Energy Scenarios under Uncertainty," in 5th International Conference on European (EEM 2008), Lisboa, Portugal 28-30 may, 2008, no. Section III.

[7] A. Soroudi and T. Amraee, "Decision making under uncertainty in energy systems: State of the art," Renew. Sustain. Energy Rev., vol. 28, pp. 376-384, 2013.

[8] S. Prpich, G., Darabkhani, H., Oakey, J., Pollard, “An investigation into future energy system risks : An industry perspective Working Paper," 2014.

[9] A. A. Akgün, E. van Leeuwen, and P. Nijkamp, "A multi-actor multi-criteria scenario analysis of regional sustainable resource policy," Ecol. Econ., vol. 78, pp. 19-28, 2012.

[10] D. Caporale and C. De Lucia, "Social acceptance of on-shore wind energy in Apulia Region (Southern Italy)," Renew. Sustain. Energy Rev., vol. 52, pp. 1378-1390, Dec. 2015.

[11] Y. Guo, P. Ru, J. Su, and L. D. Anadon, "Not in my backyard, but not far away from me: Local acceptance of wind power in China," Energy, vol. 82, pp. 722-733, Mar. 2015.

[12] F. Ribeiro, P. Ferreira, M. Araújo, and A. C. Braga, "Public opinion on renewable energy technologies in Portugal," Energy, vol. 69, pp. 39-50, May 2014.

[13] R. Schaeffer, A. S. Szklo, A. F. P. Lucena, B. S. M. C. Borba, L. P. P. Nogueira, F. P. Fleming, A. Troccoli, M. Harrison, and M. S. Boulahya, "Energy sector vulnerability to climate change: A review," Energy, vol. 38, no. 1, pp. 1-12, Feb. 2012.

[14] K. Pilli-Sihvola, P. Aatola, M. Ollikainen, and H. Tuomenvirta, "Climate change and electricity consumption-Witnessing increasing or decreasing use and costs?," Energy Policy, vol. 38, no. 5, pp. 2409-2419, May 2010.

[15] A. F. P. Lucena, A. S. Szklo, R. Schaeffer, and R. M. Dutra, "The vulnerability of wind power to climate change in Brazil," Renew. Energy, vol. 35, no. 5, pp. 904-912, 2010.

[16] A. F. P. Lucena, A. S. Szklo, R. Schaeffer, R. R. de Souza, B. S. M. C. Borba, I. V. L. da Costa, A. O. P. Júnior, and S. H. F. da Cunha, "The vulnerability of renewable energy to climate change in Brazil," Energy Policy, vol. 37, pp. 879-889, 2009.

[17] S. Ludig, E. Schmid, M. Haller, and N. Bauer, "Assessment of transformation strategies for the German power sector under the uncertainty of demand development and technology availability,” Renew. Sustain. Energy Rev., vol. 46, pp. 143-156, 2015.

[18] I. J. Pérez-Arriaga, "Managing large scale penetration of intermittent renewables," in MIT Energy Initiative Symposium, 2011. 
[19] P. G. Levi and M. G. Pollitt, "Cost trajectories of low carbon electricity generation technologies in the UK: A study of cost uncertainty," Energy Policy, vol. 87, pp. 48-59, Dec. 2015

[20] R. Loulou, M. Labriet, and A. Kanudia, "Deterministic and stochastic analysis of alternative climate targets under differentiated cooperation regimes," Energy Econ., vol. 31, no. 2009, pp. S131-S143, 2009.

[21] Y. P. Cai, G. H. Huang, Z. F. Yang, and Q. Tan, "Identification of optimal strategies for energy management systems planning under multiple uncertainties," Appl. Energy, vol. 86, no. 4, pp. 480-495, Apr. 2009.

[22] S. Kim, J. Koo, C. J. Lee, and E. S. Yoon, "Optimization of Korean energy planning for sustainability considering uncertainties in learning rates and external factors," Energy, vol. 44, no. 1, pp. 126-134, 2012.

[23] E. B. Cedeño and S. Arora, "Performance comparison of Transmission Network Expansion Planning under deterministic and uncertain conditions," Int. J. Electr. Power Energy Syst., vol. 33, no. 7, pp. 1288-1295, 2011.

[24] S. C. Bankes, "Exploratory Modeling and the use of Simulation for Policy Analysis." 1992.

[25] J. H. Kwakkel and E. Pruyt, "Exploratory Modeling and Analysis, an approach for model-based foresight under deep uncertainty," Technol. Forecast. Soc. Change, vol. 80, no. 3, pp. 419-431, Mar. 2013.

[26] Ian Wilson, "Mental maps of the future: an intuitive logics approach to scenarios," in Learning from the Future: Competitive Foresight Scenarios, L. Fahey and R. M. Randall, Eds. John Wiley \& Sons, Inc., 1998, pp. 81-108.

[27] S. Casadei, L. Liucci, and D. Valigi, "Hydrological Uncertainty and Hydro-power : New Methods to Optimize the Performance of the Plant," Energy Procedia, vol. 59, pp. 263 $269,2014$.

[28] REN - Redes Energéticas Nacionais, "PDIRT Plano de Desenvolvimento e investimento da Rede de Transporte de Eletricidade 2014-2023," 2013.

[29] DGEG - Direção Geral de Energia e Geologia, "Relatório de Monitorização da Segurança de Abastecimento do Sistema Elétrico Nacional 2013-2030,” 2013.

[30] EDP Distribuição, "Plano de desenvolvimento e investimento da rede de distribuição (PDIRD) 2015-2019," 2014.

[31] M. Amer, T. U. Daim, and A. Jetter, "A review of scenario planning," Futures, vol. 46, pp. 23-40, 2013.

[32] S. Pereira, P. Ferreira, and A. I. F. Vaz, "Optimization modeling to support renewables integration in power systems," Renew. Sustain. Energy Rev., vol. 55, pp. 316-325, Mar. 2016.

[33] P. A. Østergaard, "Reviewing optimisation criteria for energy systems analyses of renewable energy integration," Energy, vol. 34, no. 9, pp. 1236-1245, Sep. 2009.

[34] REN - Redes Energéticas Nacionais, "Estatísticas do setor elétrico," Electricidade Centro de Informação, 2015. [Online]. Available:

http://www.centrodeinformacao.ren.pt/PT/Paginas/CIHomePage.aspx.

[35] Governo de Portugal, "Compromisso para o Crescimento Verde (CCV)," Ministério do Ambiente, Ordenamento do Território e Energia (MAOTE), 2014. [Online]. Available: http://www.crescimentoverde.gov.pt/. [Accessed: 15-Dec-2015]. 
[36] N. Sun, D. J. Swider, and A. Voss, "A Comparison of Methodologies Incorporating Uncertainties into Power Plant Investment Evaluations," in 29th IAEE International Conference. Potsdam, Germany, 7-10 june, 2006.

[37] A. A. Salisu and T. O. Ayinde, "Modeling energy demand: Some emerging issues," Renew. Sustain. Energy Rev., vol. 54, pp. 1470-1480, Feb. 2016.

[38] J. Pérez-García and J. Moral-Carcedo, "Analysis and long term forecasting of electricity demand trough a decomposition model: A case study for Spain," Energy, vol. 97, pp. 127-143, Feb. 2016.

[39] J. N. Maack, "Chapter 5. Scenario Analysis: A Tool for Task Managers," Washington, D.C., 2001.

[40] W. E. Walker, R. J. Lempert, and J. H. Kwakkel, "Deep Uncertainty,” Encycl. Oper. Res. Manag. Sci., vol. 1, no. 1, pp. 395-402, 2008.

[41] M. Noori, S. Gardner, and O. Tatari, "Electric vehicle cost, emissions, and water footprint in the United States: Development of a regional optimization model," Energy, vol. 89, pp. 610-625, 2015.

[42] C. Hamarat, J. H. Kwakkel, and E. Pruyt, "Adaptive Robust Design under deep uncertainty," Technol. Forecast. Soc. Change, vol. 80, no. 3, pp. 408-418, Mar. 2013.

[43] A. Schröder, F. Kunz, J. Meiss, R. Mendelevitch, and C. von Hirschhausen, "Current and Prospective Costs of Electricity Generation until 2050," Data Documentation 68, 2013.

[44] EVALUE - Estudos e Projectos em Ambiente e Economia S.A. and CENSE - Center for Environmental and Sustainability Research, "Novas tecnologias energéticas Roadmap Portugal2050: Análise das novas tecnologias energéticas nacionais e cenarização do seu impacto no sistema energético nacional," 2011.

[45] INESCPORTO - Instituto de Engenharia de Sistemas e Computadores do Porto and ATKearney, "Recomendações para uma estratégia sustentável de eficiência energética e exploração de energias renováveis para Portugal," 2012.

[46] UCTE - Union for the Co-ordination of Transmission of Electricity, "System Adequacy Forecast 2009 - 2020 Executive Summary," 2009.

[48] Palisade Corporation, "Risk Analysis and Simulation Add-In for Microsoft Excel Version 7,"User's Guide@Risk. 2015. 


\section{ANNEX I}

The optimization model used in this work assumes a cost minimization approach, with the following objective function:

$$
\begin{aligned}
\sum_{t \in T} \sum_{n \in N}\left[\left(I c_{n} \frac{j(1+j)^{l t n}}{(1+j)^{l t n}-1}+\operatorname{CFOM}_{n}\right) I p_{n t}(1+j)^{-t}\right] & \\
& +\sum_{t \in T} \sum_{m \in M} \sum_{i \in I}\left[\left(\operatorname{CVOM}_{i}+F_{i}+C p_{i}+E C \times C O_{2_{i}}\right) P_{i, m, t} \Delta_{m}(1+j)^{-t}\right]
\end{aligned}
$$

where:

- $\quad T$ is a set of the time period (in years) considered in the model

- $\quad N$ is a set of the new power plants to be included in the system

- $\quad M$ is the set of months per year of planning

- $I$ is the set of all power plants

- $\quad I c_{n}$ is the $n$ new power plant investment cost $(€ / \mathrm{MW})$

- $\quad j$ is the annual discount rate

- $\quad l t n$ is the $n$ new power plant lifetime (years)

- CFOM $_{n}$ is the Operation and Management (O\&M) fixed cost of the $n$ type of power plant $(€ / \mathrm{MW})$

- $I p_{n, t}$ is the installed power of plant $n$ in year $t(\mathrm{MW})$

- $C V O M_{i}$ is the variable O\&M costs for each $i$ type of power plant (€/MWh)

- $\quad C_{p i}$ is the cost of pumping for each $i$ type of power plant (€/MWh)

- $F_{i}$ is the fuel cost for each $I$ type of power plant ( $\left.€ / \mathrm{MWh}\right)$

- $E C$ is the $\mathrm{CO}_{2}$ emission allowance cost (€/ton)

- $\mathrm{CO}_{2 i}$ is the $\mathrm{CO}_{2}$ emission factor of type $i$ power plant (ton/MWh)

- $\quad P_{i, m, t}$ is the power output from power plant $i$ in month $m$ of year $t$ (MW)

- $\Delta_{m}$ is the number of hours for month $m$.

The assumptions included in the optimization model follows:

- Information about economic and technical aspects of each power unit is presented in Table 4. All costs related issues were collected from [44] which provides a relatively recent survey of current and future cost estimates in the electricity sector, covering renewable and non-renewable generation. All costs are assumed to remain constant for the next 20 years and so, the technology learning effect and the variations in fuel prices are not considered.

- $\mathrm{CO}_{2}$ emission factors were calculated from the ratio between annual emissions release by each thermal power plant and its respective annual electricity production. $\mathrm{CO}_{2}$ emissions from biomass were considered to be negligible.

- The assumed potential for RES until 2030 were obtained from a project designated New Energy Technologies - Roadmap Portugal 2050 [44].

- $\mathrm{CO}_{2}$ emissions allowances are assumed to remain unchanged at $25 € /$ ton $\mathrm{CO}_{2}$, as well as the discount rate, which was set at $8 \%$ [45].

- The reserve margin used in this study was defined to be 5\% [46]. The reserve margin constraint is included in the model to ensure the reliability of the system and allows to consider the diversification of energy sources.

- The minimum share of RES in the annual power production is assumed to be $62 \%$, a value close the one obtained in 2014 for the Portuguese system. 
The model includes also set of constraints from physical processes, demand requirements, capacity limitations and legal/policy impositions as described in [32].

Table 4 - Technical and economic characteristics of each power plant. Sources: [32] and [43].

\begin{tabular}{|c|c|c|c|c|c|c|c|c|}
\hline Power plant & $\begin{array}{c}\text { Investment } \\
\text { cost }(€)\end{array}$ & $\begin{array}{c}\text { FO\&M } \\
\text { costs } \\
(€ / \mathrm{MWh})\end{array}$ & $\begin{array}{c}\text { VO\&M } \\
\text { costs } \\
(€ / \mathrm{MW})\end{array}$ & $\begin{array}{c}\text { Pumping } \\
\text { costs } \\
(€ / \mathrm{MWh})\end{array}$ & $\begin{array}{c}\text { Fuel } \\
\text { costs } \\
(€ / \mathrm{MWh})\end{array}$ & $\begin{array}{c}\mathrm{CO}_{2} \\
\text { emission } \\
\text { factor } \\
(\mathrm{t} / \mathrm{MWh})\end{array}$ & $\begin{array}{c}\text { Lifetime } \\
\text { (years })\end{array}$ & $\begin{array}{c}\text { Potential } \\
\text { until } 2035 \\
(\mathrm{MW})\end{array}$ \\
\hline Coal & 1800000 & 60000 & 6 & - & 8,4 & 0,844 & 40 & - \\
\hline CCGT & 800000 & 20000 & 4 & - & 21,6 & 0,369 & 30 & - \\
\hline Large hydro & 3000000 & 20000 & - & - & - & - & 50 & \\
\hline $\begin{array}{c}\text { Large hydro } \\
\text { w/ pumping }\end{array}$ & 2000000 & 20000 & - & 1,5 & - & - & 50 & 4595 \\
\hline Run-of-river & 3000000 & 60000 & - & - & - & - & 50 & 2650 \\
\hline $\begin{array}{c}\text { Wind } \\
\text { onshore }\end{array}$ & 1300000 & 35000 & - & - & - & - & 25 & 2600 \\
\hline $\begin{array}{c}\text { Wind } \\
\text { offshore }\end{array}$ & 3000000 & 80000 & - & - & - & - & 20 & 4000 \\
\hline Solar PV & 1560000 & 25000 & - & - & - & - & 25 & 9035 \\
\hline Minihydro & 3000000 & 60000 & - & - & - & - & 40 & 400 \\
\hline Biomass & 2500000 & 100000 & - & - & - & - & 30 & 1042 \\
\hline
\end{tabular}

\section{ANNEX II}

Table 5 - Parameters of each PDF. Source [47].

\begin{tabular}{|l|l|c|}
\hline Probability Function & Parameters & Mean value \\
\hline Beta & $\begin{array}{l}\text { - shape parameters } \alpha_{1} \text { and } \alpha_{2} \\
\text { - minimum value } \\
\text { - maximum value }\end{array}$ & $\min +\frac{\alpha_{1}}{\alpha_{1}+\alpha_{2}}(\max -\min )$ \\
\hline Exponential & $-\beta$ value & $\beta$ \\
\hline Gamma & $\begin{array}{l}\text { - shape parameters } \alpha \\
\text { - scale parameter } \beta\end{array}$ \\
\hline Inverse Gaussian & $\begin{array}{l}\text { - mean parameter } \mu \\
\text { - shape parameter } \lambda\end{array}$ & $\mu$ \\
\hline Pearson & $\begin{array}{l}\text { - shape parameters } \alpha \\
\text { - scale parameter } \beta\end{array}$ & $\frac{\beta}{\alpha-1}$ \\
\hline Triangular & $\begin{array}{l}\text { - minimum value } \\
\text { - most likely value } \\
\text { - maximum value }\end{array}$ & $\frac{\min +\operatorname{mik} \text { likely }+ \text { max }}{3}$ \\
\hline Uniform & $\begin{array}{l}\text { - minimum value } \\
\text { - maximum value }\end{array}$ & $\begin{array}{l}\text { - shape parameters } \alpha \\
\text { - scale parameter } \beta\end{array}$ \\
\hline Weibull & & where $\Gamma$ is the Gamma function. \\
\hline
\end{tabular}

